\title{
ANALYSIS OF THE LACTATION CURVE OF MURRAH BUFFALOES WITH MIXED NON-LINEAR MODELS
}

Carlos Luna-Palomera ${ }^{1}$, Joel Domínguez-Viveros ${ }^{2 \mathrm{a} *}$, Guadalupe Nelson Aguilar-Palma ${ }^{2 \mathrm{~b}}$, Francisco Castillo-Rangel ${ }^{2 c}$, Fernando Sánchez-Dávila ${ }^{3}$, and Ulises Macías-Cruz ${ }^{4}$

${ }^{1}$ Universidad Juárez Autónoma de Tabasco. División Académica de Ciencias Agropecuarias. Villahermosa, Tabasco, Mexico https://orcid.org/0000-0002-0465-8622

${ }^{2 a}$ Universidad Autónoma de Chihuahua. Facultad de Zootecnia y Ecología. Chihuahua, Chihuahua, Mexico https://orcid.org/0000-0002-4011-6142

${ }^{2 b}$ Universidad Autónoma de Chihuahua. Facultad de Zootecnia y Ecología. Chihuahua, Chihuahua, Mexico https://orcid.org/0000-0002-1654-8930

${ }^{2 c}$ Universidad Autónoma de Chihuahua. Facultad de Zootecnia y Ecología. Chihuahua, Chihuahua, Mexico https://orcid.org/0000-0002-1894-067X

${ }^{3}$ Universidad Autónoma de Nuevo León. Facultad de Agronomía. Monterrey, Nuevo León, Mexico https://orcid.org/0000-0003-1576-6845

${ }^{4}$ Universidad Autónoma de Baja California. Instituto de Ciencias Agrícolas. Mexicali, Baja California, Mexico https://orcid.org/0000-0002-6947-2247

*Corresponding author E-mail: jodominguez@uach.mx - joeldguezviveros@yahoo.com.mx

\section{ABSTRACT}

This study aimed to evaluate the lactation curve of female Murrah buffaloes, using mixed nonlinear models (NLM), across three lactation periods ( $180 \mathrm{~d}, 210 \mathrm{~d}$, and $240 \mathrm{~d})$. A total of 5334 data on daily milk production $(\mathrm{kg})$ were analyzed. The data were collected every seven days in the interval of one to 250 days of lactation, corresponding to 221 lactations and 145 females, with calvings from 2017 to 2019. The data came from a herd located in the Centro municipality, Tabasco, Mexico. Five NLM were evaluated: Wood (WOD), Wiltmink (WIL), Cobby (COB), Brody (BRO), Sikka (SIK). The best fit model was selected based on the mean prediction error, mean absolute percentage error (MAPE), prediction error variance, coefficient of determination $\left(R^{2}\right)$, concordance correlation coefficient (CCC), Akaike (AIC) and Bayesian (BIC) information criteria. A regression analysis was performed between the observed and predicted values. All the NLM had a $R^{2}$ above 0.91 . They tend to underestimate the predictions, without residual autocorrelation. The MAPE showed an average value of $23.5 \%$. The best fit model was WOD, followed by SIK and BRO. For WIL and COB, the mixed model did not improve the fitting. The shortest lactation period showed the best fit, followed by the $210 \mathrm{~d}$ and $240 \mathrm{~d}$ periods. The relationship between observed:predicted values fluctuated from 0.65 to 1.00 , with an average value of 0.94 . The use of NLM transcended in the AIC and BIC. The evaluated models showed goodness of fit, with good predictability, but low values in accuracy and precision of prediction.

Key words: Bubalinoculture, lactation period, milk production, model selection, tropical cattle. 


\section{INTRODUCTION}

The precise and proper prediction of milk production and performance of offspring is an important pre-requisite in selecting genetically superior animals for the dairy industry. Lactation curves (LCs) describe milk production based on four components: initial production, ascending phase, or increased production, maximum or peak production, and descending rate or reduced production, called persistency. Nonlinear models (NLM) are used to characterize and analyze LCs. The regression coefficients are associated to the components and allow to derive other descriptive LC indicators (Papajcsik and Bodero, 1988; Landete-Castillejos and Gallego, 2000; Macciotta et al., 2011), which can be useful in handling, feeding, and breeding programs.

The fitting of NLM has been performed using a non-linear regression analysis with iterative methods (Bates and Watts, 1988). The milk production variable represents a particular case of repeated measures over time, with variance and covariance structures. The data structure is unbalanced, with possible implications in the statistical assumptions of residuals and the certainty of the regression coefficients associated to the model. The non-linear regression does not consider possible sources of variation associated with the animal (Wang and Zuidhof, 2004; Domínguez-Viveros et al., 2017; Vélez et al., 2019). As an alternative to evaluate an LC, the fitting of mixed NLM has been proposed, including sources of variation associated with the animal (Hossein-Zadeh, 2016; PalaciosEspinosa et al., 2016; Piccardi et al., 2017). The variability in milk production occurs due to genetic and environmental effects, which define and characterize the LC. However, those genetic and environmental effects can change during the lactation period, or, in specific cases, depend on the lactation length (LL) (Madalena, 1988).

The buffalo Murrah breed is a milk type animal, native to India, and the most widespread breed worldwide. Murrah buffaloes are jet black. Male adults can weigh $800 \mathrm{~kg}$, while females can weigh $600 \mathrm{~kg}$. Regarding milk production, lactation can extend from 180 to 305 days, with an average daily production of $5 \mathrm{~kg}$ and a fat percentage of $7.3 \%$ (Borghese, 2005; FAO, 2010). In Mexico, the production of buffaloes occurs in the tropical and subtropical regions, and breeders are organized in the Asociación Mexicana de Criadores de Búfalos (AMEXBU, 2019). This study aimed to characterize the lactation period and curve type of female buffaloes as well as determine the production levels and possible sources of variation associated with the animal.

\section{MATERIALS AND METHODS}

A total of 5,334 observations on daily milk production $(\mathrm{kg})$ were analyzed. Data were collected every seven days in the interval of one to 250 days of lactation, corresponding to 221 lactations and 145 female buffaloes, with calvings from 2017 to 2019. These data were obtained from a herd located (La Carolina Ranch) in the Centro municipality, Tabasco, Mexico, grazing native pasture on floodplains and lagoon banks, in a warm-humid climate with summer rains (mean annual precipitation of $2332 \mathrm{~mm}$ ), and a mean annual temperature of $26.1^{\circ} \mathrm{C}$.

To analyze and characterize the LC, five NLM were evaluated (Ramírez-Valverde et al., 1998; Landete-Castillejos and Gallego, 2000; García-Muñiz et al., 2008): Wood, (WOD; $y_{t}$ $\left.=\beta_{1}^{*}\left(t^{\beta 2}\right)^{*}\left(\exp \left(-\beta_{3}{ }^{*} \mathrm{t}\right)\right)\right) ;$ Wiltmink, (WIL; $\mathrm{y}_{\mathrm{t}}=\beta_{1}$ $\left.+\beta_{2}{ }^{*} t+\beta_{3}{ }^{*}\left(\exp \left(-0.05^{*} t\right)\right)\right)$; Cobby, $\left(\mathrm{COB} ; \mathrm{y}_{\mathrm{t}}=\beta_{1}-\right.$ $\left.\beta_{2}{ }^{*} \mathrm{t}-\beta_{1}{ }^{*}\left(\exp \left(-\beta_{3}{ }^{*} \mathrm{t}\right)\right)\right) ;$ Brody, $\left(\mathrm{BRO} ; \mathrm{y}_{\mathrm{t}}=\beta_{1}{ }^{*}(\exp (-\right.$ $\left.\left.\left.\beta_{2}{ }^{*} \mathrm{t}\right)\right)-\beta_{1}{ }^{*}\left(\exp \left(-\beta_{3}{ }^{*} \mathrm{t}\right)\right)\right) ;$ and Sikka, $\left(\mathrm{SIK}_{;} \mathrm{y}_{\mathrm{t}}=\right.$ $\left.\beta_{1}^{*}\left(\exp \left(\left(\beta_{2}{ }^{*} t\right)-\left(\beta_{3}{ }^{*} t^{2}\right)\right)\right)\right)$. Where: $y_{t}=$ corresponds to the milk production $(\mathrm{kg})$ at day $\mathrm{t} ; \beta_{1^{\prime}} \beta_{2^{\prime}}$ and $\beta_{3}=$ are the regression coefficients that comprise each model. Three lactation periods or LL, 180, 210 and 240 days ( $180 \mathrm{~d}, 210 \mathrm{~d}$, and $240 \mathrm{~d}$ ) were evaluated, based on two analyses (ANA1, ANA2), using the NLMIXED procedure in Statistical Analysis System v9.0 (Wolfinger, 1999; Ching-Fan et al., 2005). ANA1 does not include the random effects related to the regression coefficients, only the random effect (e) of residuals. ANA2 included the random effect associated with the female buffalo, which corresponds to the $\beta_{1}$ of each model, in addition to the residuals. The random effects (e and $\beta_{1}$ ) adhere to the non-correlation assumptions, with a normal distribution, mean equal to zero, and variances equal to $\sigma^{2}$ and $\sigma^{2}{ }_{\beta 1}$.

The selection of the model with the best fit was made with the coefficient of determination $\left[R^{2}=(1\right.$ - (rss/tss))], the Akaike information criterion [AIC $=-2^{*} \log$ lik $\left.+2 \mathrm{k}\right]$, and the Bayesian information criterion [BIC $\left.=-2^{*} \log \operatorname{lik}+\log (n)^{*} k\right]$. The residuals were evaluated with the mean prediction error $\quad\left[\mathrm{MPE}=\left(\sum_{\mathrm{i}=1}^{\mathrm{n}}\left(\frac{\text { odp }-\mathrm{edp}}{\text { odp }}\right) * 100\right) / \mathrm{n}\right]$, the mean absolute percentage error [MAPE $\left.=\left(\sum_{\mathrm{i}=1}^{\mathrm{n}}\left(\left|\frac{\mathrm{odp}-\mathrm{edp}}{\text { odp }}\right|\right) * 100\right) / \mathrm{n}\right]$, the prediction error variance $\left[\mathrm{PEV}=\sum_{\mathrm{i}=1}^{\mathrm{n}}(\mathrm{odp}-\mathrm{edp})^{2} / \mathrm{n}\right]$, and the Durbin-Watson statistic [DW $=2(1$ $\left.-\rho) ; \rho=\frac{\sum_{t=2}^{n}\left(e_{t}-e_{t-1}\right)^{2}}{\sum_{t=1}^{n} e_{t}{ }^{2}}\right]$ to analyze the error autocorrelations (Motulsky and Christopoulos, 2004; Palacios-Espinosa et al., 2016; Piccardi et al., 2017).

Where: odp = observed daily production; edp 
= estimated daily production; $\mathrm{n}=$ total number of observations; rss = residual sum of squares; tss = total sum of squares; Log lik = logarithm of the likelihood function; $\mathrm{k}=$ number of parameters in the model. For the MPE, PEV, AIC, and BIC, the model with the lowest values was considered as the best fit. The prediction capacity of the NLM was validated by analyzing the linear relationship between the edp and the odp based on the correlation between the two $(\Upsilon)$ and the regression analysis based on the model: odp $=$ $\beta 0+\beta \mathrm{i}_{\text {edp }}$; where $\beta 0$ is the intercept, and $\beta \mathrm{i}$ is the slope or change rate of the odp for each change unit in the edp. Additionally, the concordance correlation coefficient was calculated $(\mathrm{CCC}=$ $2^{*} \sigma_{\text {odp }, \text { edp }} /\left(\sigma_{\text {odp }}^{2}+\sigma_{\text {edp }}^{2}+\left(\bar{y}_{\text {odp }}-\bar{y}_{\text {edp }}\right)^{2}\right) ;$ which takes values from 0 to 1 and jointly measures the accuracy and precision of a model (Lin, 1989; Khan et al., 2012). With the results from ANA2, the production variables related to the $\mathrm{LC}$ were generated: initial production; accumulated total production (PTOTAL); maximum production at peak lactation; days until maximum production; mean daily production.

\section{RESULTS AND DISCUSSION}

Tables 1, 2, and 3 show the results of statistical criteria used to select the best fit model for each LL. As goodness of fit, all the models explained $91 \%$ or more of the variability in the analyzed data, since their $\mathrm{R}^{2}$ was equal to or greater than

Table 1. Fit of non-linear models in the analysis of the lactation curve at 180 days of female Murrah buffaloes.

\begin{tabular}{|c|c|c|c|c|c|}
\hline Item & WOD & WIL & COB & BRO & SIK \\
\hline \multicolumn{6}{|c|}{ Analysis one, non-linear models not including random effects } \\
\hline$\beta_{1}$ & 4.6677 & 6.5267 & 6.0960 & 6.1185 & 5.7245 \\
\hline$\beta_{2}$ & 0.09473 & -0.01179 & 0.008379 & 0.001538 & 0.000600 \\
\hline$\beta_{3}$ & 0.003033 & -1.3824 & 1.1093 & 1.0741 & 0.000012 \\
\hline AIC & 15909 & 15912 & 15963 & 15970 & 15939 \\
\hline BIC & 15934 & 15938 & 15989 & 15996 & 15964 \\
\hline $\mathrm{R}^{2}$ & 0.93 & 0.93 & 0.92 & 0.92 & 0.91 \\
\hline MEP & -7.6 & -7.5 & -7.7 & -7.6 & 2.7 \\
\hline MAPE & 23.9 & 23.8 & 24.1 & 24.3 & 22.5 \\
\hline PEV & 2.17 & 2.18 & 2.20 & 2.21 & 2.49 \\
\hline DW & 0.78 & 0.78 & 0.79 & 0.77 & 0.94 \\
\hline$\Upsilon$ & 0.29 & 0.29 & 0.27 & 0.26 & 0.27 \\
\hline$\beta \mathrm{i}$ & 0.99 & 0.99 & 0.98 & 0.99 & 0.65 \\
\hline $\mathrm{CCC}$ & 0.15 & 0.15 & 0.14 & 0.13 & 0.18 \\
\hline \multicolumn{6}{|c|}{ Analysis two, non-linear models including the $\beta 1$ random effect } \\
\hline$\beta_{1}$ & 4.6677 & 6.5267 & 6.0960 & 6.1726 & 5.7245 \\
\hline$\beta_{2}$ & 0.09915 & -0.01179 & 0.008379 & 0.001639 & 0.000613 \\
\hline$\beta_{3}$ & 0.003103 & -1.3824 & 1.1093 & 0.9621 & 0.000012 \\
\hline AIC & 15838 & 15914 & 15965 & 15908 & 15869 \\
\hline BIC & 15870 & 15948 & 15997 & 15940 & 15901 \\
\hline $\mathrm{R}^{2}$ & 0.93 & 0.93 & 0.92 & 0.92 & 0.91 \\
\hline MEP & -9.0 & -7.6 & -7.7 & -7.7 & 2.8 \\
\hline MAPE & 24.3 & 23.9 & 24.1 & 24.1 & 22.6 \\
\hline PEV & 2.18 & 2.17 & 2.20 & 2.20 & 2.50 \\
\hline DW & 0.78 & 0.78 & 0.79 & 0.79 & 0.94 \\
\hline$\Upsilon$ & 0.29 & 0.29 & 0.27 & 0.26 & 0.27 \\
\hline$\beta \mathrm{i}$ & 0.98 & 0.99 & 0.98 & 0.93 & 0.65 \\
\hline $\mathrm{CCC}$ & 0.16 & 0.15 & 0.14 & 0.14 & 0.18 \\
\hline
\end{tabular}

$\beta_{1}, \beta_{2}$, and $\beta_{3}$, regression coefficients that comprise the evaluated non-linear models. AIC, Akaike information criterion. BIC, Bayesian information criterion. $\mathrm{R}^{2}$, coefficient of determination. MPE, mean prediction error. MAPE, mean absolute percentage error. PEV, prediction error variance. DW, Durbin-Watson statistic. $\Upsilon$, correlation coefficient between the observed and estimated values. $\beta \mathrm{i}$, slope or change rate of the observed value for each change unit in the estimated value, product of the linear regression analysis. CCC, concordance correlation coefficient. Models: WOD, Wood; WIL, Wiltmink; COB, Cobby; BRO, Brody; SIK, Sikka. 
Table 2. Fit of non-linear models in the analysis of the lactation curve at 210 days of female Murrah buffaloes.

\begin{tabular}{lccccc}
\hline \multicolumn{1}{c}{ Item } & WOD & WIL & COB & BRO & SIK \\
\hline Analysis one, non-linear models not including rand & effects & & \\
$\beta_{1}$ & 4.7005 & 6.4911 & 6.1440 & 6.1656 & 5.7903 \\
$\beta_{2}$ & 0.09171 & -0.01140 & 0.008984 & 0.001664 & 0.000134 \\
$\beta_{3}$ & 0.00296 & -1.3204 & 0.7535 & 0.9849 & 0.000008985 \\
AIC & 17395 & 17399 & 17456 & 17466 & 17433 \\
BIC & 17421 & 17425 & 17482 & 17492 & 17459 \\
R $^{2}$ & 0.93 & 0.93 & 0.93 & 0.93 & 0.93 \\
MEP & -7.4 & -7.5 & -7.3 & -7.6 & -4.7 \\
MAPE & 23.4 & 23.4 & 23.5 & 23.6 & 22.8 \\
PEV & 2.05 & 2.01 & 2.10 & 2.10 & 2.11 \\
DW & 0.75 & 0.75 & 0.76 & 0.77 & 0.77 \\
$\Upsilon$ & 0.34 & 0.34 & 0.33 & 0.32 & 0.33 \\
$\beta$ & 0.99 & 1.00 & 0.96 & 0.99 & 0.89 \\
CCC & 0.21 & 0.20 & 0.19 & 0.19 & 0.21 \\
Analysis two, non-linear models & including the & random effect & & \\
$\beta_{1}$ & 4.6154 & 6.4911 & 6.1260 & 6.2882 & 5.8059 \\
$\beta_{2}$ & 0.09956 & -0.001140 & 0.008837 & 0.001855 & 0.000156 \\
$\beta_{3}$ & 0.003118 & -1.3204 & 1.0572 & 0.5938 & 0.000009345 \\
AIC & 17233 & 17401 & 17457 & 17319 & 17272 \\
BIC & 17265 & 17434 & 17489 & 17352 & 17304 \\
R $^{2}$ & 0.93 & 0.93 & 0.93 & 0.93 & 0.92 \\
MEP & -7.4 & -7.3 & -7.5 & -7.4 & -4.2 \\
MAPE & 23.4 & 23.4 & 23.5 & 23.6 & 22.7 \\
PEV & 2.05 & 2.06 & 2.08 & 2.09 & 2.11 \\
DW & 0.75 & 0.75 & 0.76 & 0.77 & 0.78 \\
$\Upsilon$ & 0.34 & 0.34 & 0.33 & 0.32 & 0.33 \\
$\beta$ & 0.96 & 1.00 & 0.98 & 0.89 & 0.86 \\
CCC & 0.21 & 0.20 & 0.19 & 0.20 & 0.21 \\
\hline
\end{tabular}

$\beta_{1}, \beta_{2}$, and $\beta_{3}$, regression coefficients that comprise the evaluated non-linear models. AIC, Akaike information criterion. BIC, Bayesian information criterion. $\mathrm{R}^{2}$, coefficient of determination. MPE, mean prediction error. MAPE, mean absolute percentage error. PEV, prediction error variance. DW, Durbin-Watson statistic. $\Upsilon$, correlation coefficient between the observed and estimated values. $\beta \mathrm{i}$, slope or change rate of the observed value for each change unit in the estimated value, product of the linear regression analysis. CCC, concordance correlation coefficient. Models: WOD, Wood; WIL, Wiltmink; COB, Cobby; BRO, Brody; SIK, Sikka.

0.91. The DW results showed no autocorrelation in the residuals, with values in the range of 0.71 to 0.94; the MAPE fluctuated from 22.5 to 24.3 , with a mean value of $23.5 \%$. For the MPE, the models tend to underestimate the predictions since they presented negative sign results (MPE of -0.42 to -0.90). However, SIK for 180d showed different results that overestimated the prediction (MPE of 2.7). For LL, the AIC- and BIC-based order selection of NLM was best fit for $180 \mathrm{~d}$, followed by $210 \mathrm{~d}$ and $240 \mathrm{~d}$; the order selection of models within LL differs across the analyses. The AIC and BIC values were lower in the WIL and COB models with ANA1; the WOD, BRO, and SIK models showed a reduction with ANA2. The model with the best fit was WOD, followed by
SIK and BRO.

As an indicator of accuracy in the predictions, the $\Upsilon$ presented estimates of medium to low magnitude, with a mean value of 0.32 . However, a positive trend was observed as LL increased. The $\beta i$ obtained from the linear regression analysis indicates the precision of the predictions. Values close to one indicate good precision; values distant to one can be associated with biases in the predictions. The results for $\beta$ i ranged from 0.65 (SIK in 180d) to 1.00 , with a mean value of 0.94 . Table 4 shows the production variables associated with the LC across periods and NLM, while Figs. 1 and 2 show the LC for the three LL through the WOD and SIK models.

LL to which the milk production system 
Table 3. Fit of non-linear models in the analysis of the lactation curve at 240 days of female Murrah buffaloes.

\begin{tabular}{|c|c|c|c|c|c|}
\hline Item & WOD & WIL & COB & BRO & SIK \\
\hline \multicolumn{6}{|c|}{ Analysis one, non-linear models not including random effects } \\
\hline$\beta_{1}$ & 4.8222 & 6.4001 & 6.1050 & 6.1586 & 5.8833 \\
\hline$\beta_{2}$ & 0.08089 & -0.01048 & 0.008563 & 0.001649 & -0.00045 \\
\hline$\beta_{3}$ & 0.002712 & -1.1585 & 1.0944 & 0.9993 & 0.000005448 \\
\hline AIC & 18349 & 18357 & 18403 & 18412 & 18398 \\
\hline $\mathrm{BIC}$ & 18376 & 18383 & 18429 & 18438 & 18424 \\
\hline $\mathrm{R}^{2}$ & 0.93 & 0.93 & 0.93 & 0.93 & 0.92 \\
\hline MEP & -7.3 & -8.9 & -7.3 & -7.4 & -7.4 \\
\hline MAPE & 23.2 & 23.9 & 23.3 & 23.4 & 23.3 \\
\hline PEV & 2.01 & 2.05 & 2.03 & 2.04 & 2.02 \\
\hline DW & 0.71 & 0.74 & 0.73 & 0.75 & 0.77 \\
\hline$\Upsilon$ & 0.37 & 0.36 & 0.36 & 0.35 & 0.35 \\
\hline$\beta$ & 0.99 & 0.83 & 0.99 & 0.99 & 0.99 \\
\hline CCC & 0.23 & 0.25 & 0.22 & 0.22 & 0.22 \\
\hline \multicolumn{6}{|c|}{ Analysis two, non-linear models including the $\beta 1$ random effect } \\
\hline$\beta_{1}$ & 4.7989 & 6.4001 & 6.1050 & 6.2527 & 5.9611 \\
\hline$\beta_{2}$ & 0.08312 & -0.01048 & 0.008563 & 0.001788 & -0.00072 \\
\hline$\beta_{3}$ & 0.002756 & -1.1584 & 1.0943 & 0.6989 & 0.000004456 \\
\hline AIC & 18168 & 18359 & 18405 & 18233 & 18222 \\
\hline $\mathrm{BIC}$ & 18200 & 18392 & 18437 & 18266 & 18255 \\
\hline $\mathrm{R}^{2}$ & 93.2 & 93.0 & 93.1 & 93.1 & 92.9 \\
\hline MEP & -7.3 & -8.9 & -7.3 & -7.4 & -7.5 \\
\hline MAPE & 23.2 & 23.9 & 23.3 & 23.4 & 23.3 \\
\hline PEV & 2.01 & 2.05 & 2.03 & 2.03 & 2.06 \\
\hline DW & 0.71 & 0.72 & 0.71 & 0.73 & 0.78 \\
\hline$\Upsilon$ & 0.37 & 0.36 & 0.36 & 0.35 & 0.35 \\
\hline$\beta$ & 0.98 & 0.83 & 0.99 & 0.92 & 0.97 \\
\hline $\mathrm{CCC}$ & 0.24 & 0.25 & 0.22 & 0.23 & 0.22 \\
\hline
\end{tabular}

$\beta_{1}, \beta_{2}$, and $\beta_{3}$, regression coefficients that comprise the evaluated non-linear models. AIC, Akaike information criterion. $\mathrm{BIC}$, Bayesian information criterion. $\mathrm{R}^{2}$, coefficient of determination. MPE, mean prediction error. MAPE, mean absolute percentage error. PEV, prediction error variance. DW, Durbin-Watson statistic. $\Upsilon$, correlation coefficient between the observed and estimated values. $\beta \mathrm{i}$, slope or change rate of the observed value for each change unit in the estimated value, product of the linear regression analysis. CCC, concordance correlation coefficient. Models: WOD, Wood; WIL, Wiltmink; COB, Cobby; BRO, Brody; SIK, Sikka.

extends has different effects. In this sense, LL to which the milk production adjusts, is the basis of adjustment factors and the definition of productive variables in genetic evaluations, with possible implications in the estimation of variance components and genetic parameters (da Silva et al., 2000; Gutiérrez-Valencia et al., 2006; Baldi et al., 2011; Santos et al., 2017). Furthermore, LL is directly related to total milk production and herd income (Suárez and Ramos, 2011; Méndez and Fraga, 2012; Safari et al., 2018), and it can affect the subsequent productive and reproductive life of females (Khan and Chaudhry, 2000; Tonhati et al., 2000; Mendes et al., 2013). Studies of other populations and different production systems have reported various results regarding production levels, such as (PTOTAL - LL): Tonhati et al. (2000), $1496 \mathrm{~kg}$ in $271 \mathrm{~d}$; Rosati and Van Vleck (2002), $2286.8 \mathrm{~kg}$ in 270 d; GutiérrezValencia et al. (2006), $1009.3 \mathrm{~kg}$ in $240 \mathrm{~d}$ and $1069.6 \mathrm{~kg}$ in $270 \mathrm{~d}$; Ramos et al. (2006), $1650 \mathrm{~kg}$ in 256 d; Suárez and Ramos (2011), 730 kg in 200 d and 869.9 in 244 d; García et al. (2012), 717 kg in $200 \mathrm{~d}$ and $860 \mathrm{~kg}$ in $244 \mathrm{~d}$; Méndez and Fraga (2012), $658 \mathrm{~kg}$ in $170 \mathrm{~d}$; Shokrollahi and Hasanpur (2014), for two populations $2184.0 \mathrm{~kg}$ and $1540 \mathrm{~kg}$ at $240 \mathrm{~d}$; Fundora (2015), $867.1 \mathrm{~kg}$ in $220 \mathrm{~d}$.

Regarding the LC analysis with NLM, the published results are diverse for the ranking and selection of models to describe the evaluated LC. Quintero-Vélez et al. (2007) reported SIK as the best fit model, followed by BRO and WOD. 
Table 4. Production levels across lactation periods and non-linear models evaluated.

\begin{tabular}{lccccc}
\hline & WOD & WIL & COB & BRO & SIK \\
\hline 180-day lactation & & & & & \\
PI & 4.65 & 5.20 & 4.08 & 4.02 & 5.72 \\
PTOTAL & 955.3 & 955.8 & 957.8 & 958.1 & 865.4 \\
PMAX & 5.88 & 5.87 & 6.04 & 6.05 & 5.72 \\
DPMAX & 27 & 31 & 10 & 10 & 1 \\
MDP & 5.31 & 5.30 & 5.32 & 5.32 & 4.81 \\
210-day lactation & & & & & \\
PI & 4.69 & 5.22 & 3.24 & 4.70 & 5.79 \\
PTOTAL & 108.3 & 1084.8 & 1085.8 & 1089.9 & 1057.8 \\
PMAX & 5.88 & 5.86 & 6.06 & 6.11 & 5.79 \\
DPMAX & 30 & 31 & 11 & 8 & 1 \\
MDP & 5.16 & 5.17 & 5.18 & 5.19 & 5.04 \\
240-day lactation & & & & & \\
PI & 4.81 & 6.24 & 4.05 & 3.88 & 5.88 \\
PTOTAL & 1210.0 & 1229.8 & 1214.5 & 1216.0 & 1212.9 \\
PMAX & 5.85 & 6.24 & 6.05 & 6.08 & 5.88 \\
DPMAX & 26 & 1 & 6 & 8 & 1 \\
MDP & 5.04 & 5.12 & 5.06 & 5.07 & 5.05 \\
\hline
\end{tabular}

Models: WOD, Wood; WIL, Wiltmink; COB, Cobby; BRO, Brody; SIK, Sikka. PI, initial production; PTOTAL, accumulated total production; PMAX, maximum production at peak lactation; DPMAX, days until maximum production; MDP, mean daily production.

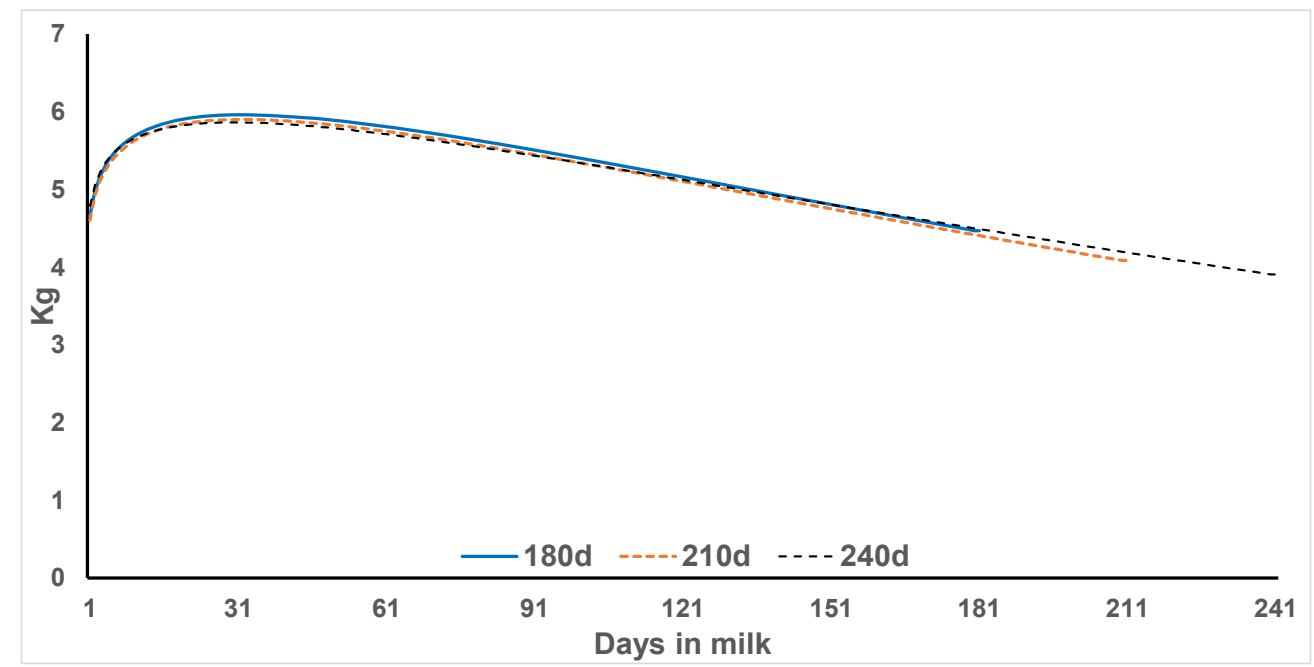

Fig. 1. Lactation curves for female Murrah buffaloes based on the Wood model at 180 (180d), 210 (210d), and 240 days (240d).

Another study conducted by Hossein-Zadeh (2016) reported Nelder and SIK as the best fit models for the first and second lactation, while the ranking of models changed for the third lactation, with WOD being the best fit, followed by Dhanoa and SIK. Additionally, El-Bramony et al. (2016) and Soysal et al. (2016) reported that WOD, followed by $\mathrm{COB}$ and WIL, were fit to describe the production of milk and its components, evaluating from one to seven lactations. AbdelSalam et al. (2011), Shokrollahi and Hasanpur (2014), and Dezfuli and Babaci (2018) showed similar results, and the WOD model was selected and applied to evaluate and characterize the LC in female buffalo populations. Other studies evaluating linear models have reported the fit 


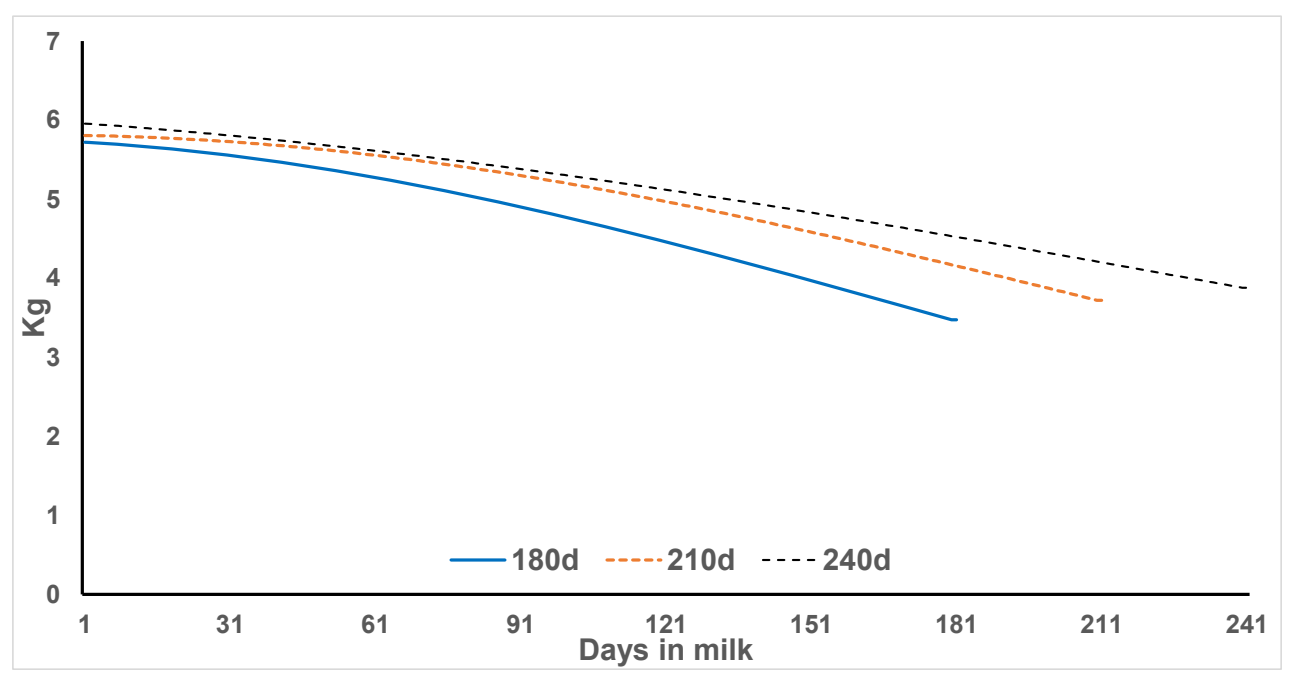

Fig. 2. Lactation curves for female Murrah buffaloes based on the Sikka model at 180 (180d), 210 (210d), and 240 days (240d).

of LC based on quadratic polynomial models and logarithmic components (Fraga et al., 2003; Muñoz et al., 2008; García et al., 2013).

The regression coefficients of the NLM associated with the production, as well as the directly and indirectly derived production variables, can be considered as selection criteria and objectives in breeding programs due to the heritability and genetic correlations estimated for those variables (Rosati and Van Vleck, 2002; Mendes et al., 2013; Safari et al., 2018). In this study, the random effect of the female buffaloes for a regression coefficient improved the fit of WOD, BRO, and SIK. However, future studies should explore the nature of these random effects and their association with genetic or environmental effects. In the ranking of models with LL, the shortest time showed the best fit, based on the AIC and BIC criteria. However, the fit of LL in the estimation of variance components and genetic parameters, as well as in the prediction of genetic values and the ordering of the sires, should be evaluated to develop breeding schemes based on selection.

The production systems of dairy buffaloes under tropical conditions depend on animal, environmental, feeding, and technological factors. In the animal context, the variability in the production levels is attributed to the genotype and additive and non-additive genetic effects as well as to the environmental effects associated with the animal when there are repeated measures over time, as is the case of LC (Tonhati et al., 2000; Ramos et al., 2006; Fooda et al., 2011). The combination of environment, feeding, and technology defines the production systems. For dairy buffaloes, the production systems transcend the humid and sub-humid tropics of America (Gutiérrez-Valencia et al., 2006; Quintero-Vélez et al., 2007; Suárez and Ramos, 2011; Mendes et al., 2013), Asia (Khan, 1997; Shokrollahi and Hasanpur, 2014; Soysal et al., 2016), and Africa (Abdel-Salam, 2011; Fooda et al., 2011; El-Bramony et al., 2016). The Member States of the South Asian Association for Regional Cooperation make up $73.8 \%$ of the world's buffalo population and the populations of the main dairy breeds, Murrah and Nili Ravi, are derived from this region (Hamid et al., 2016).

\section{CONCLUSIONS}

Including the variance associated with the animal transcended in the Akaike and Bayesian information criteria, the evaluated models showed goodness of fit, with good predictability, but low values in accuracy and precision of prediction. The lactation curve of female Murrah buffaloes was fitted to the WOD model, followed by SIK, for the periods of 180, 210, and 240 days.

\section{LITERATURE CITED}

Abdel-Salam, S.A.M., W. Mekkawy, Y.M. Hafez, A.A. Zaki, and S. Abou-Bakr. 2011. Fitting lactation curve of Egyptian buffalo using three different models. Egypt. J. Anim. Prod. 48:119-133.

AMEXBU. 2019. Asociación Mexicana de Criadores de Búfalos. Available at: $<w w w$. amexbu.org.mx>. Accessed on Jul. 1, 2020. 
Baldi, F., L.M.M. Massolini, G.D.G. Mansan, B.A. Braga, B.R.R. Aspilcueta, and L.G. de Albuquerque. 2011. Effect of lactation length adjustment procedures on genetic parameter estimates for buffalo milk yield. Genet. Mol. Biol. 34:62-67.

Bates, D.M., and D.G. Watts. 1988. Nonlinear regression analysis and its applications. Vol. 2. New York, Wiley. USA.

Borghese, A. 2005. Buffalo production and research. Consiglio per la ricercar e la sperimentazione in agricultura, Roma, Italia. Available at: http://www.istanbulmanda. org/wp-content/uploads/2015/06/BORGESEAVRUPA-MANDA-SAYISI.pdf

Ching-Fan, S., C. Cheng-Te, and W. Wen-Chung. 2005. Using SAS PROC NLMIXED to fit item response theory models. Behav. Res. Meth. 37:202-218.

da Silva, V.R., M.L. Martínez, and R.L. Teodoro. 2000. Cow and sire evaluation from Gyr breed based on partial records of milk production. Rev. Brasil. Zoot. 29:1060-1066.

Dezfuli, B.T., and M. Babaci. 2018. Fitting five models to describe milk production curve for Khuzestani buffaloes of Iran in different parities and seasons. Buffalo Bulletin. 37:513526.

Domínguez-Viveros, J., A.R. Urbina-Valenzuela, A. Palacios-Espinoza, N. Callejas-Juárez, J.A. Ortega-Gutiérrez, J.L. EspinozaVillavicencio, et al. 2017. Characterization of growth of Cebu cattle in testing performance on grazing. Ecosist. Recur. Agrop. 4:341-348.

El-Bramony, M.M., H.A. El-Regalaty, A.A. Ashmawy, and K.M. Mourad. 2016. Prediction of lactation curve pattern for daily milk, fat, and protein yields in Egyptian buffalo. Egypt. J. Anim. Prod. 53:1-12.

FAO. 2010. La situación de los recursos zoo genéticos mundiales para la alimentación y la agricultura. Roma, Italia. Available at: https://www.fao.org/3/a1250s/a1250s00.htm

Fooda, T.A., A.R. Elbeltagy, R.L. Hassan, and S.S. Awad. 2011. Assessment of Egyptian buffaloes crossing with Pakistani and Italian buffaloes for some production traits. J. Amer. Sci. 7:269-276.

Fraga, L.M., M. Gutiérrez, L. Fernández, O. Fundadora, y M.E. González. 2003. Estudio preliminar de las curvas de lactancia en búfalas mestizas Murrah. Rev. Cubana Ciencia Agríc. 37:151-155.

Fundora, O. 2015. Performance of river buffaloes (Bubalus bubalis) from Buffalypso breed in feeding systems based on grazing: fifteen years of research in the Instituto de Ciencia Animal. Rev. Cubana Ciencia Agríc. 49:161-171.
García, Y., L.M. Fraga, G. Guzmán, M. Mora, D. García y E. Padrón. 2012. Evaluación del comportamiento lechero de búfalas mestizas (Buffalypso x Carabao). Rev. Cubana Ciencia Agríc. 46:357-363.

García, Y., L.M. Fraga, G. Guzmán, M. Mora, D. García y E. Padrón. 2013. Estimación de la curva media de lactancia de búfalas mestizas (Buffalypso x Carabao). Rev. Cubana Ciencia Agríc. 47:131-136.

García-Muñiz, J.G., E.G. Martínez-González, R. Núñez-Domínguez, R. Ramírez-Valverde, R. López-Ordaz, and A. Ruiz-Flores. 2008. Comparison of equations to fit lactation curves of cattle. Rev. Cient. FCV-LUZ 18:160169.

Gutiérrez-Valencia, A., N. Hurtado-Lugo, and M. Cerón-Muñoz. 2006. Estimates of correction factors for lactation length, age, and calving season in buffaloes of Colombian Atlantic coast. Livest. Res. Rural Develop. 18:e50

Hamid, M.A., S. Ahmed, M.A. Rahman, and K.M. Hossain. 2016. Review article. Status of buffalo production in Bangladesh compared to SAARC countries. Asian J. Anim. Sci. 10:313-329

Hossein-Zadeh, N.G. 2016. Modelling lactation curve for milk fat to protein ratio in Iranian buffaloes (Bubalus bubalis) using non-linear mixed models. J. Dairy Res. 83:334-340.

Lin, L.I.K. 1989. A concordance correlation coefficient to evaluate reproducibility. Biometrics 45:255-268.

Khan, M.S. 1997. Response to selection for milk yield and lactation length in buffaloes. AsianAust. J. Anim. Sci. 10:567-570.

Khan, M.S, and H.Z. Chaudhry. 2000. Lactating length and its behaviour in Nili-Ravi buffaloes. Pakistan Vet. J. 20:81-84.

Khan, M.K., H.T. Blair, and N. Lopez-Villalobos. 2012. Lactation curves of different cattle breeds under cooperative dairying conditions in Bangladesh. J. Applied Anim. Res. 40:179-185.

Landete-Castillejos, T., and L. Gallego. 2000. Technical note: the ability of mathematical models to describe the shape of lactation curves. J. Anim. Sci. 78:3010-3013.

Macciotta, N.P.P., C. Dimauro, S.P.G. Rassu, R. Steri, and G. Pulina. 2011. The mathematical description of lactation curves in dairy cattle. Italy J. Anim. Sci. 10:213-224.

Madalena, F.E. 1988. A note on the effect of variation of lactation length on the efficiency of tropical cattle selection for milk yield. Theo. Applied Genet. 76:830-834. 
Mendes, M.C.H., M.A.C. Mendes, R.A. de Amorim, C.P.L. Souza, J.C. de Souza, and A. Pala. 2013. Genetic parameters for milk yield, lactation length and calving intervals of Murrah buffaloes from Brazil. Rev. Brasil. Zoot. 42:565-569.

Méndez, M., and L.M. Fraga. 2012. Milk yield and fat percentage at the control day in river buffalo cows in the Granma province. Arch. Zoot. 61:11-18.

Motulsky, H, and A. Christopoulos. 2004. Fitting models to biological data using linear and nonlinear regression: a practical guide to curve fitting. Oxford University Press, San Diego, USA.

Muñoz, B.M., H. Tonhati, B.R. Aspilcueta, and N. Hurtado-Lugo. 2008. Use of some mathematical models to study the lactation curve of Murrah buffaloes and their crossbreds under extensive system in the state of Sao Paulo. Livest. Res. Rural Develop. 20:e142.

Palacios-Espinosa, A., J. Domínguez-Viveros, Y. Padrón-Quintero, M. Rodríguez-Castro, F.A. Rodríguez-Almeida, J.L. EspinozaVillavicencio, et al. 2016. Characterization of lactation curves in Siboney cattle using nonliear mixed models. Rev. Mexi. Cienc. Pecu. 7:233-242.

Papajcsik, I.A., and J. Bodero. 1988. Modelling lactation curves of Friesian cows in a subtropical climate. Animal Prod. 47:201-207.

Piccardi, M., R. Macchiavelli, F.A. Capitaine, G.A. Bó, and M. Balzarini. 2017. Fitting milk production curves through nonlinear mixed models. J. Dairy Res. 84:146-153.

Quintero-Vélez, J., G.J. Serna, and M. CerónMuñoz. 2007. Nonlinear mixed models to describe buffalo milk yield curve in an organic production system in Magdalena medio Antioqueño (Colombia). Livest. Res. Rural Develop. 19:e52.

Ramírez-Valverde, R., G. Ramírez-Valverde, R. Núñez-Domínguez, and A. TewoldeMedhin. 1998. Lactation curves in Angus, Brown Swiss, and their crossbred cows: II. Comparison of equations. Agrociencia 32:325-330.

Ramos, A.A., M.C.H. Mendes, C.P.L. Souza, H.C. Goncalves, and A.D.M.M. Ribeiro. 2006. Caracterização fenotípica e genética da produção de leite e do intervalo entre partos em bubalinos da Raça Murrah. Pesq. Agrop. Brasil. 41:1261-1267.
Rosati, A., and L.D. Van Vleck. 2002. Estimation of genetic parameters for milk, fat, protein, and mozzarella cheese production in Italian river buffalo population. Livest. Prod. Sci. 74:185-190.

Safari, A., N.G. Hossein-Zadeh, A.A. Shadparvar, and R.A. Arpanahi. 2018. A review on breeding and genetic strategies in Iranian buffaloes. Trop. Anim. Health Prod. 50:707714 .

Santos de, S.A.C., R.M.P. de Goncalves, C.P.L. Souza, C.B. Machado, and M.C.H. Mendes. 2017. Editing and modeling of milk production data for genetic evaluation of Murrah buffaloes. Pesq. Agrop. Brasil. 52:1261-1267.

Shokrollahi, B., and K. Hasanpur. 2014. Study of individual lactation patterns of Iranian dairy buffaloes. J. Agric. Rural Develop. Trop. Subtrop. 115:125-133.

Soysal, M.I., E.K. Gurcan, and M. Aksel. 2016. The comparison of lactation curve with different models in Italian origined water buffalo herd raised in Istanbul province of Turkey. J. Tekirdag Agric Fac. 13:139-144.

Suárez, M.A., and F. Ramos. 2011. Characterization of productive and reproductive performance in buffaloes Buffalypso in Cuba. Zoot. Trop. 29:485-494.

Tonhati, H., F.B. Vasconcellos, and L.G. Albuquerque. 2000. Genetic aspects of productive and reproductive traits in a Murrah buffalo herd in São Paulo, Brazil. J. Anim. Breed. Genet. 117:331-336.

Velez, T.O.M., G.H. Sanchez, and Salamanca A. 2019. Growth curves modeling of multirracial replacement milk heifers reared under pasture tropical conditions. Arch. Zoot. 68:88-98.

Wang, Z., and M.J. Zuidhof. 2004. Estimation of growth parameters using a nonlinear mixed Gompertz model. Poultry Sci. 83:847-852.

Wolfinger, R.D. 1999. Fitting nonlinear mixed models with the new NLMIXED procedure. Proceedings $24^{\text {th }}$ Annual SAS Users Group International Conference 287:278-284. 